\title{
Factors that discourage medical students from pursuing a career in psychiatry
}

\author{
Marie T. Curtis-Barton, ${ }^{1}$ John M. Eagles ${ }^{2}$
}

The Psychiatrist (2011), 35, 425-429, doi: 10.1192/pb.bp.110.032532

${ }^{1}$ University of Aberdeen, ${ }^{2}$ Royal Cornhill Hospital, Aberdeen

Correspondence to John M. Eagles (john.eagles@nhs.net)

First received 7 Sep 2010, final revision 16 Feb 2011, accepted 28 Jun 2011

\begin{abstract}
Aims and method This cross-sectional study investigated the evolution of intentions among medical students to pursue a career in psychiatry and the factors that might discourage them from becoming a psychiatrist. A questionnaire survey was sent to medical students in years 1-5 at Aberdeen University.
\end{abstract}

Results From 918 students, 467 (51\%) returned useable responses. Proportions of students across the 5-year groups who definitely or probably intended to become psychiatrists remained fairly stable at $4-7 \%$. In their final year, psychiatry remained a possible career option for a further $17 \%$ of students. The most potent discouraging factor was the perception of poor prognoses among psychiatric patients. Perceptions of a lack of scientific/evidence base reduced enthusiasm for becoming a psychiatrist. Issues relating to the prestige of the specialty were also important.

Implications If recruitment to the specialty is to improve, these negative perceptions among students should be addressed by their teachers and more widely within psychiatry.

Declaration of interest None.
Poor recruitment of doctors into psychiatry in the UK has recently been described as a 'crisis', highlighted by the dwindling numbers of graduates from British universities sitting the MRCPsych exam. ${ }^{1}$ The issue is not a new one in that for many years psychiatry has failed to attract adequate recruits both in the UK and elsewhere. ${ }^{2-4}$ Factors underlying this recruitment problem are complex and are likely to include medical student selection, undergraduate exposure to the specialty, postgraduate experiences and wider issues such as the public and professional image of psychiatry and psychiatrists. $^{1-9}$ This paper will focus predominantly on factors arising during medical student training.

With only a few exceptions, studies have found that students' attachments/clerkships in psychiatry give rise to more positive attitudes towards the specialty. ${ }^{10-15}$ It is simplistic, however, to equate more positive attitudes with necessarily an increased likelihood of pursuing a psychiatric career, ${ }^{9,16,17}$ and this likelihood does appear to decrease as medical students go through their training. Among sixthform school pupils who were prospective medical students, for those stating a career intention, psychiatry was the fourth most popular choice. ${ }^{18}$ In contrast, it is among the least popular of clinical specialty choices made by medical students. ${ }^{19,20}$ Although some of this difference may be explicable in terms of the type of school student who applies successfully to medical school, the change also suggests that factors are at play during the medical student years that reduce enthusiasm for a career in psychiatry. The nature of these factors is incompletely understood, and little is known as to how and when they might emerge during undergraduate training. The current study investigated some of these factors in the hope that this might lead to rational approaches towards enhancing recruitment into psychiatry.

\section{Method}

From the existing literature, a questionnaire was designed to investigate medical students' views about: (a) psychiatry and psychiatrists; (b) role models; (c) their likelihood of pursuing a career in psychiatry; and (d) factors that might discourage them from becoming a psychiatrist. This paper will report the findings relating to items (c) and (d).

The questionnaire was piloted electronically on 27 medical students who were pursuing an intercalated BSc Med Sci degree. All of these students responded and the questionnaire was modified in response to comments. Respondents reported that the questionnaire took about 10 min to complete.

Following questions designed to elicit views about psychiatrists and psychiatry, students were asked: 'Do you think you will specialise in psychiatry?' and were given response options of 'Definitely', 'Probably', 'Possibly', 'Probably not' and 'Definitely not'.

Factors that might discourage students from pursuing a career in psychiatry were then presented. The seven factors selected derived from earlier studies of foundation doctors in Scotland. ${ }^{21}$ In these studies, 31 factors had been listed that may have influenced career choice and these 7 factors 


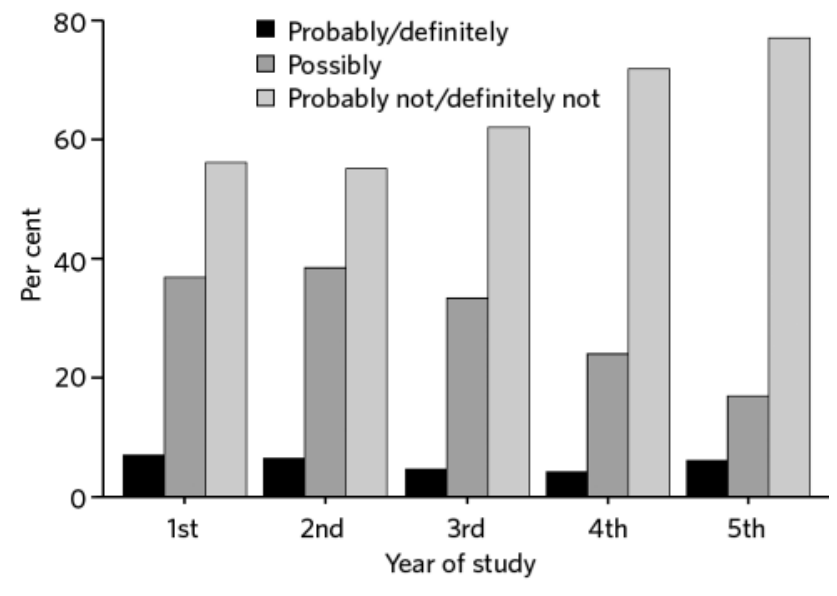

Fig. 1 Students' responses by year of study to the question: 'Do you think you will specialise in psychiatry?'

emerged as those rated more negatively than positively with regard to a potential career in psychiatry.

Students were asked: 'Which of the following discourages you from choosing psychiatry as a career?' The listed items were:

- standing of psychiatrists among the general public

- standing of psychiatrists among the medical profession

- comments by other specialists about psychiatry

- amount of paperwork/bureaucracy in psychiatry

- scientific basis of psychiatry

- a perceived lack of evidence base

- prognosis of patients in psychiatry.

The response options given were: 'Not at all', 'A little', or 'A lot'.

With the exception of the intercalating BSc Med Sci students who had been involved in completing the pilot questionnaire, all medical students in first to fifth years at Aberdeen University were sent questionnaires electronically in February 2010, following prenotification about the survey. Reminders were sent after 2 and 7 days. Following the electronic survey, paper versions of the questionnaire were made available to non-respondents at lectures and clinical teaching sessions. All electronic and paper responses were anonymous. Ethical approval was obtained from Aberdeen University's College of Life and Sciences and Medicine Review Board.

\section{Results}

From 918 students, 416 electronic and 54 paper responses were received. Of the total of 470 responses, 467 were completed adequately yielding a 50.9\% useable response rate. Responses across the years varied from a high of $65 \%$ among first-year students to a low of $43 \%$ among second-year students. Female response rates at $56 \%$ exceeded those from male students at $44 \%$.

Responses to the question: 'Do you think you will specialise in psychiatry?' are shown, by year group, in Fig. 1 . Responses of 'Probably' and 'Definitely' are collapsed, as are those of 'Probably not' and 'Definitely not'.
The percentage of students who definitely or probably intend to become a psychiatrist remains essentially level at between 4 and $7 \%$ across the five undergraduate years. Progressive proportions of students decide that psychiatry is not the career for them but by the final year, in addition to the $6 \%$ who deem it a probable or definite career choice, another $17 \%$ were still considering psychiatry as a possibility.

Table 1 shows the responses of all students to the questions about factors that may discourage them from choosing a career in psychiatry. More than half of students were put off by perceptions about the evidence base and the scientific basis of psychiatry, and the prognosis of psychiatric patients was the most discouraging perception.

To establish changes that may occur across the 5 years of undergraduate training, responses were analysed by chisquared tests for trend. Of the seven potentially discouraging factors, five showed no significant change, but decreasing proportions of students became discouraged by a perceived lack of evidence base $(P<0.001)$ and by the amount of paperwork/bureaucracy in psychiatry $(P=0.023)$.

\section{Discussion}

This study had the merit of eliciting views from students across the undergraduate years and thus having the potential to show evolution of career intentions and perceptions of factors that might reduce enthusiasm for a career in psychiatry. The response rate, although reasonable for a survey of this type, was just over $50 \%$. It is quite possible that non-respondents had less positive attitudes to psychiatry and would have been less likely to have entertained the specialty as a potential career choice; female response rates were higher than those from males, and we know that women generally tend to have more positive attitudes towards psychiatry and to a psychiatric career. $^{22}$ Practical factors, such as the proximity of examinations for second-year medical students and the dispersal of final-year students to geographically distant placements, may well have adversely influenced response rates in our study. Although the questionnaire came from the first author with no stated departmental affiliation, respondents may have been influenced by perceiving that psychiatry was involved in conducting the study.

It would have been potentially instructive to have had comparative information on the development of career choice for other specialties. In the absence of such data it is difficult to know whether the increase in those who would probably or definitely not wish to pursue a career in psychiatry (from $56 \%$ in the first year to $77 \%$ in the final year) reflects a reduction in enthusiasm towards psychiatry or increasing crystallisation of other career options. In The Netherlands, Tijdink et $a l^{23}$ noted a decrease in interest in a psychiatric career as medical students went through their training and felt this to be in keeping with an increasing focus on other particular specialty choices.

The proportion of students with a probable or definite intention of becoming a psychiatrist stayed fairly level across the undergraduate years. Although it seems more likely, from what we know about formation of specialty choice, that individual students fluctuate in their career 
Table 1 Students' responses to the question: 'Which of the following discourages you from choosing psychiatry as a career?'

\begin{tabular}{|c|c|c|c|}
\hline & \multicolumn{3}{|c|}{$\%$} \\
\hline & Not at all & A little & A lot \\
\hline Standing of psychiatrists among the general public & 70 & 28 & 2 \\
\hline Standing of psychiatrists among the medical profession & 63 & 31 & 6 \\
\hline Comments by other specialists about psychiatry & 69 & 26 & 5 \\
\hline Amount of paperwork/bureaucracy in psychiatry & 52 & 37 & 11 \\
\hline Scientific basis of psychiatry & 47 & 35 & 18 \\
\hline A perceived lack of evidence base & 49 & 37 & 14 \\
\hline Prognosis of patients in psychiatry & 38 & 42 & 20 \\
\hline
\end{tabular}

intentions, it is possible that the same students start and finish their medical student years with a psychiatric career in mind. A longitudinal study would be required to clarify this possibility.

The focus of this paper is on factors that may influence medical students to become psychiatrists. However, the findings also raise issues about student selection and postgraduate recruitment, and these points will be covered briefly.

\section{Medical student selection}

In Maidment et al's study ${ }^{18}$ of sixth formers contemplating a career in medicine, only $25 \%$ deemed psychiatry to be a 'not very attractive' career option and $14 \%$ indicated that they would definitely not wish to become a psychiatrist. Comparison of these responses with those from our firstyear students suggests that successful applicants to medical school may differ from unsuccessful applicants or that, less plausibly, students become rapidly less keen on a career in psychiatry after only a few months at medical school. Brockington \& Mumford $^{2}$ and Malhi et $a l^{6}$ have suggested that a focus on medical student selection processes is a very important component of enhancing recruitment into psychiatry.

\section{Postgraduate recruitment}

Although it is worth re-emphasising that our figures may be inflated due to higher response rates from students more positively disposed towards psychiatry, 6 months before graduating $6 \%$ of final-year students considered psychiatry to be a definite or probable career choice and a further $17 \%$ deemed it to be a possibility that they might become a psychiatrist. Recruiting only a relatively small proportion of these 'possibles' would solve our current workforce problems.

Confirming earlier studies, ${ }^{2,7,24,25}$ Goldacre et $a l^{26}$ recently found that psychiatry has continued to recruit 'late choosers' among UK graduates of the 1990s. Exposure to psychiatry as a foundation doctor markedly increases enthusiasm for a career in the specialty ${ }^{21}$ and we should thus continue to advocate an increase in numbers of psychiatric foundation posts, especially within the earlier placements before applications for specialist training are made.

\section{Influences on students' career choices}

Our findings confirm that the standing of psychiatry among the public and among medical colleagues detracts from the attractiveness of our specialty for students. ${ }^{3,8,27,28}$ These factors are, presumably, quite closely related to students' exposure to negative comments ('bad mouthing') about psychiatry and psychiatrists; such comments are not confined to psychiatry but have been reported as exerting a negative effect on perceptions of a career in bad-mouthed specialties. $^{29,30}$ However, only a small percentage of students endorsed the feeling that either the prestige of psychiatry or the prevalence of negative comments discouraged them 'a lot'. Addressing these perceptions and behaviours is a complex issue and of clear importance beyond the confines of recruitment of psychiatrists.

The amount of paperwork and bureaucracy in psychiatry put off $37 \%$ of students 'a little' and $11 \%$ 'a lot'. However, as students progressed through medical school, this factor became less discouraging probably as students appreciated that other specialties (notably general practice) may share this problem to a similar or greater extent.

Other studies have also found that perceptions of a lack of basis in evidence and/or science has a negative effect on students' enthusiasm to pursue a psychiatric career. $^{3,6,9,19,28,31}$ More than half of our student sample was put off a career in psychiatry by these perceptions. It was encouraging that students became less discouraged by a perceived lack of evidence base; possibly this relates in part to fourth-year Aberdeen students' participation in preparation and presentation of an evidence-based case study in psychiatry.

Students' perceptions of the prognosis of patients in psychiatry was the most negatively rated factor in our study, discouraging $42 \%$ 'a little' and $20 \%$ 'a lot' from becoming a psychiatrist. Other studies support patient prognosis as a negative influence on attitudes and recruitment. ${ }^{9,27,31,32}$ In Denmark, ${ }^{32}$ students rated the degree to which they deemed treatment methods to be effective. Perceptions of the effectiveness of psychiatric treatment improved after 4week psychiatric attachments but were still well below ratings for surgery, medicine and general practice. Perhaps 
not surprisingly, first-year medical students were found to rank the ability to help patients as their most important determinant of specialty choice, ${ }^{27}$ emphasising how crucial perceptions of prognosis may be to recruitment.

\section{Implications for recruiting medical students to psychiatry}

Although this paper has focused on discouraging factors that we can seek to modify, clearly the positive aspects of a psychiatric career should be emphasised to students. The 'big three' attractive factors in choosing psychiatry are hours and conditions of work, doctors' assessments of their own aptitudes and their experience of psychiatry as a student. ${ }^{33}$ From a recruitment perspective it is thus vital that we identify and encourage students with aptitude for psychiatry, emphasise the positives of a career in the specialty and do all we can to optimise their undergraduate experiences. $^{7}$

With regard to prestige and bad-mouthing, perhaps anti-stigma campaigners have not yet focused sufficiently on students and other healthcare professionals. ${ }^{8}$ Discouragement through a perceived lack of science and evidence base can be addressed by introducing more of the underlying science (including psychology and sociology as well as neuroscience) into psychiatric teaching at an early stage and by emphasising the firm evidence base underlying much of psychiatric practice. Concomitantly, we must ensure that the attractions of rewarding interactions with patients in a holistic person-based specialty ${ }^{3}$ continue to be flagged up to students.

Negative perceptions about the prognosis of patients in psychiatry stood out as the most discouraging factor. It is difficult to address the issue of prognosis generically across psychiatric diagnoses, especially when the effectiveness of psychiatric interventions differs hugely between different disorders. ${ }^{34}$ Although it is likely that the prognosis and the effectiveness of treatment for patients seen by psychiatrists is rather better than those seen in most areas of general medicine, this would contrast starkly with the views of medical students. ${ }^{32}$ The desirability of exposing students to patients with good prognoses was emphasised 30 years ago, ${ }^{35}$ and it may be helpful if psychiatric educators consciously introduce information about prognosis to teaching sessions.

\section{Acknowledgements}

This paper derives from the first author's thesis for her BSc Med Sci degree at Aberdeen University. We are grateful to Neil Scott for his statistical assistance and to John Lemon for his input into the electronic survey. We thank the study participants and Lana Hadden who did the secretarial work for this paper.

\section{About the authors}

Ms Marie T. Curtis-Barton (BSc Med Sci) is a medical student at the University of Aberdeen. Professor John M. Eagles (MPhil, FRCPsych) is a consultant psychiatrist at the Royal Cornhill Hospital, Aberdeen.

\section{References}

1 Oxtoby K. Psychiatry in crisis. BMJ Careers 2008; 27 August (http:// careers.bmj.com/careers/advice/view-article.html?id=3050).

2 Brockington IF, Mumford DB. Recruitment into psychiatry. Br J Psychiatry 2002; 180: 307-12.

3 Malhi GS, Parker GB, Parker K, Kirkby KC, Boyce $P$, Yellowlees $P$, et al. Shrinking away from psychiatry? A survey of Australian medical students' interest in psychiatry. Aust NZ J Psychiatry 2002; 36: 416-23.

4 Sierles FS, Taylor MA. Decline of US medical student career choice of psychiatry and what to do about it. Am J Psychiatry 1995; 152: 1416-21.

5 Sierles FS, Dinwiddie SH, Patroi D, Atre-Vaidya N, Schrift MJ, Woodard $\mathrm{JL}$. Factors affecting medical student career choice of psychiatry from 1999 to 2001. Acad Psychiatry 2003; 27: 260-8.

6 Malhi GS, Parker GB, Parker K, Carr VJ, Kirkby KC, Yellowlees P, et al. Attitudes towards psychiatry among students entering medical school. Acta Psychiatr Scand 2003; 107: 424-9.

7 Eagles JM, Wilson S, Murdoch JM, Brown T. What impact do undergraduate experiences have upon recruitment into psychiatry? Psychiatr Bull 2007; 31: 70-2.

8 Brown TM, Addie K, Eagles JM. Recruitment into psychiatry: views of consultants in Scotland. Psychiatr Bull 2007; 31: 411-3.

9 Balon R, Franchini GR, Freeman PS, Hassenfeld IN, Keshavan MS, Yoder E. Medical students' attitudes and views of psychiatry; 15 years later. Acad Psychiatry 1999; 23: 30-6.

10 Calvert S, Sharpe M, Power M, Lawrie SM. Does undergraduate education have an effect on Edinburgh medical students' attitudes to psychiatry and psychiatric patients? J Nerv Ment Dis 1999; 187: 757-61.

11 Galletly CA, Schrader GD, Chesterman HM, Tsourtos G. Medical student attitudes to psychiatry: lack of effect of psychiatric hospital experience. Med Educ 1995; 29: 449-51.

12 Creed F, Goldberg D. Students' attitudes towards psychiatry. Med EduC 1987; 21: 227-34.

13 Alexander DA, Eagles JM. Changes in attitudes towards psychiatry among medical students: correlation of attitude shift with academic performance. Med Educ 1990; 24: 452-60.

14 Singh SP, Baxter $\mathrm{H}$, Standen $\mathrm{P}$, Duggan $\mathrm{C}$. Changing the attitudes of "tomorrow's doctors" towards mental illness and psychiatry: comparison of two teaching methods. Med Educ 1998; 32: 115-20.

15 McParland M, Noble LM, Livingston G, McManus C. The effect of a psychiatric attachment on students' attitudes to and intention to pursue psychiatry as a career. Med Educ 2003; 37: 447-54.

16 Sajid A, Khan MM, Shakir M, Moazam-Zaman R, Ali A. The effect of clinical clerkship on students' attitudes toward psychiatry in Karachi, Pakistan. Acad Psychiatry 2009; 33: 212-4.

17 Balon R. Does a clerkship in psychiatry affect medical students' attitudes towards psychiatry? Acad Psychiatry 2008; 32: 73-5.

18 Maidment R, Livingston G, Katona M, Whitaker E, Katona C. Carry on shrinking: career intentions and attitudes to psychiatry of prospective medical students. Psychiatr Bull 2003; 27: 30-2.

19 Rajagopal S, Rehill KS, Godfrey E. Psychiatry as a career choice compared with other specialties: a survey of medical students. Psychiatr Bull 2004; 28: 444-6.

20 Gowans MC, Glazier L, Wright BJ, Brennels FR, Scott IM. Choosing a career in psychiatry: factors associated with a career interest in psychiatry among Canadian students on entry to medical school. Can J Psychiatry 2009; 54: 557-64.

21 Shah P, Brown TM, Eagles JM. Choosing psychiatry: factors influencing career choice among foundation doctors in Scotland. In Teaching Psychiatry to Undergraduates (ed TM Brown \& JM Eagles): 255-63. RCPsych Publications, 2011.

22 Wilson S, Eagles JM. The feminisation of psychiatry: changing gender balance in the psychiatric workforce. Psychiatr Bull 2006; 30: 321-3.

23 Tijdink JK, Soethout MB, Koerselman GF, ten Cate TJ. The interest shown by medical students and recently qualified doctors in a career in psychiatry. Tijdschrift voor Psychiatrie 2008; 50: 9-17. 
24 Cameron P, Persad E. Recruitment into psychiatry: a study of the timing and process of choosing psychiatry as a career. Can J Psychiatry 1984; 29: $676-80$.

25 Goldacre MJ, Lambert TW. Stability and change in career choices of junior doctors: postal questionnaire surveys of the United Kingdom qualifiers of 1993. Med Educ 2000; 34: 700-7.

26 Goldacre MJ, Laxton L, Lambert TW. Medical graduates' early career choices of specialty and their eventual specialty destinations: UK prospective cohort studies. BMJ 2010; 340: c3199.

27 Baboolal NS, Hutchinson GA. Factors affecting future choice of specialty among first-year medical students of the University of the West Indies, Trinidad. Med Educ 2007; 41: 50-6.

28 Wigney $T$, Parker G. Medical student observations on a career in psychiatry. Aust NZ J Psychiatry 2007; 41: 726-31.

29 Hunt DD, Scott C, Zhong S, Goldstein E. Frequency and effect of negative comments ("badmouthing") on medical students' career choices. Acad Med 1996; 71: 665-9.
30 Kamien BA, Bassiri M, Kamien M. Doctors badmouthing each other. Does it affect medical students' career choices? Aust Fam Physician 1999; 28: $576-9$.

31 Robertson T, Walter G, Soh N, Hunt G, Cleary M, Malhi G. Medical students' attitudes towards a career in psychiatry before and after viewing a promotional DVD. Australas Psychiatry 2009; 17: 311-7.

32 Holm-Petersen C, Vinge S, Hansen J, Gyrd-Hansen D. The impact of contact with psychiatry on senior medical students' attitudes toward psychiatry. Acta Psychiatr Scand 2007; 116: 308-11.

33 Goldacre, MJ, Turner G, Fazel S, Lambert T. Career choices for psychiatry: national surveys of graduates of 1974-2000 from UK medical schools. Br J Psychiatry 2005; 186: 158-64.

34 Andrews G, Issakidis C, Sanderson K, Corry J, Lapsley H. Utilising survey data to inform public policy: comparison of the cost-effectiveness of treatment of ten mental disorders. Br J Psychiatry 2004; 184: 526-33.

35 Eagle PF, Marcos LR. Factors in medical students' choice of psychiatry. Am J Psychiatry 1980; 137: 423-7. 